\title{
The effects of aerosols on precipitation and dimensions of subtropical clouds: a sensitivity study using a numerical cloud model
}

\author{
A. Teller and Z. Levin \\ Department of Geophysics and Planetary Sciences, Tel-Aviv University, Tel-Aviv, Israel
}

Received: 11 July 2005 - Published in Atmos. Chem. Phys. Discuss.: 22 August 2005

Revised: 27 October 2005 - Accepted: 9 December 2005 - Published: 12 January 2006

\begin{abstract}
Numerical experiments were carried out using the Tel-Aviv University 2-D cloud model to investigate the effects of increased concentrations of Cloud Condensation $\mathrm{Nu}$ clei $(\mathrm{CCN})$, giant $\mathrm{CCN}(\mathrm{GCCN})$ and Ice Nuclei (IN) on the development of precipitation and cloud structure in mixedphase sub-tropical convective clouds. In order to differentiate between the contribution of the aerosols and the meteorology, all simulations were conducted with the same meteorological conditions.
\end{abstract}

The results show that under the same meteorological conditions, polluted clouds (with high $\mathrm{CCN}$ concentrations) produce less precipitation than clean clouds (with low CCN concentrations), the initiation of precipitation is delayed and the lifetimes of the clouds are longer. GCCN enhance the total precipitation on the ground in polluted clouds but they have no noticeable effect on cleaner clouds. The increased rainfall due to GCCN is mainly a result of the increased graupel mass in the cloud, but it only partially offsets the decrease in rainfall due to pollution (increased $\mathrm{CCN}$ ). The addition of more effective IN, such as mineral dust particles, reduces the total amount of precipitation on the ground. This reduction is more pronounced in clean clouds than in polluted ones.

Polluted clouds reach higher altitudes and are wider than clean clouds and both produce wider clouds (anvils) when more IN are introduced. Since under the same vertical sounding the polluted clouds produce less rain, more water vapor is left aloft after the rain stops. In our simulations about 3.5 times more water evaporates after the rain stops from the polluted cloud as compared to the clean cloud. The implication is that much more water vapor is transported from lower levels to the mid troposphere under polluted conditions, something that should be considered in climate models.

Correspondence to: A. Teller

(amit@storm.tau.ac.il)

\section{Introduction}

The role of aerosols in modifying clouds and precipitation has been one of the most intriguing questions in cloud physics and in the study of climate change. Most publications to date show that increasing Cloud Condensation $\mathrm{Nu}$ clei $(\mathrm{CCN})$ concentrations leads to higher cloud drop concentrations (Twomey, 1959), to smaller effective radii and to longer-lived clouds (Albrecht, 1989; Ramanathan et al., 2001). In spite of these and many other studies, the effects of aerosols on precipitation amounts, has been made mostly through hypothesis or through the use of numerical models.

There are only very few reported statistical valid observations that deal with the relationship between the properties of the aerosol population and their effects on precipitation. Warner and Twomey (1967) studied the effects of sugar cane fires on precipitation amounts downwind. Although some changes in cloud properties were reported, the study failed to conclusively show that association could be found between cane fires and rainfall amounts (Warner, 1968). Others such as Woodcock and Jones (1970) also showed that the effect of the smoke could not explain statistically the reduction of precipitation and other factors such as meteorological conditions could have been responsible for the observed changes.

More recent studies using remote sensing observations of cloud properties in regions with and without air pollution in Australia (Rosenfeld, 2000), statistical analysis of rain events in orographic conditions (Givati and Rosenfeld, 2004) and field observations in cold orographic clouds (Borys et al., 2003) revealed that increased pollution from anthropogenic sources leads to a decrease in rainfall and snowfall. However, the difficulty of detecting changes in precipitation from satellite observations has been highlighted by Ayers (2005) who reported that no rain was recorded on the ground in the area and the time analyzed by Rosenfeld (2000).

Another aspect of the cloud-aerosol system, which needs to be addressed, is the potential effect of large and giant CCN

(C) 2006 Author(s). This work is licensed under a Creative Commons License. 
from natural sources (such as sea salt and mineral dust) on clouds and precipitation.

Hobbs et al. (1970) and Hindman et al. (1977a, b) reported that the addition of small concentrations of large $\mathrm{CCN}$ into warm clouds lead to the appearance of large drops and possibly to enhanced precipitation. Mather (1991) observed the appearance of large drops in the mixed phase clouds forming above the plume of a paper mill. This led him to propose that hygroscopic seeding could be an effective way to enhance precipitation.

Recent remote sensing analysis using NOAA-AVHRR retrievals from the Aral Sea (Rudich et al., 2002) showed that clouds affected by salt-containing dust particles develop larger cloud drop effective radius as compared with clouds in the same region that are not affected by such large aerosols. The implication is that the former clouds can promote more precipitation.

Modeling studies on the effects of large and giant $\mathrm{CCN}$ (GCCN) concentrations on precipitation were carried out by a number of investigators (Feingold et al., 1999; Philips et al., 2002; Yin et al., 2002; Khain et al., 2004; Khain and Pokrovsky, 2004; Levin et al., 2005). All these studies showed that increasing the $\mathrm{CCN}$ concentration has a suppression effect on precipitation. Some of these studies have also shown that added small concentrations of GCCN cause enhancement of precipitation from stratocumulus clouds (Feingold et al., 1999) and cumulonimbus clouds (Yin et al., 2000, 2002; Levin et al., 2005).

It is apparent from the above studies that the differences in the effect of anthropogenic air pollution on rainfall could be related to differences in the properties of the polluting particles (chemistry, concentrations and size distributions). However, other effects such as various changes in meteorological conditions could not be ruled out.

Furthermore, one more aspect that should be taken into account in evaluating the effects of aerosols on clouds is the contribution of ice nuclei (IN), such as mineral dust, in the upper regions of the clouds. Increasing the concentrations of such IN could lead to rain enhancement or suppression. Rosenfeld et al. (2001) showed using remote sensing observations that dust storms containing large amounts of $\mathrm{CCN}$ and IN tend to reduce the effective radius of particles near cloud top and to reduce precipitation as interpreted from TRMM. Van den Heever et al. (2005) tested the effects of dust particles acting as both GCCN and IN on large Florida convective clouds. Using the Regional Atmospheric Modeling System (RAMS) they showed that the accumulated surface precipitation from a cloud field is initially greater in the cases in which the GCCN and/or IN concentrations are enhanced than in the simulation run of a clean case. However, at the end of the simulation, the accumulated precipitation is greatest in the clean case, demonstrating the reduction in surface precipitation associated with increases in aerosol concentrations. These results demonstrated that dust modi- fied the spatial and temporal distribution of the rainfall on the ground.

In addition to their effects on precipitation amounts, aerosols also influence the spatial dimensions of clouds, such as cloud horizontal extent (normally named cloud fraction as seen from space) and cloud height. Using MODIS data, Koren et al. (2005) and Kaufman et al. (2005), showed that the increases in aerosol optical depth, corresponding to increases in aerosol concentrations over the Atlantic Ocean during summer months lead to increases in the height and cloud fraction of convective and stratus clouds, and to a decrease in cloud drop effective radii.

Ackerman et al. (2000) simulated the cloud cover above the Indian Ocean and found that the addition of large concentrations of absorbing aerosols such as black carbon reduces cloudiness (the semi-direct effect). On the other hand, Norris (2001) studied the historical weather records in the same region and showed that cloudiness was not affected by air pollution. Furthermore, McFarquhar et al. (2004) showed that aerial coverage of polluted clouds and cloud top heights in the Indian Ocean are lower than pristine clouds.

The conflicting results reported in the above references illustrate that much work is still needed to clarify the effects of pollution on clouds morphology and precipitation and to identify the relative role of the aerosols versus the effects of the local meteorology.

For the purpose of isolating the microphysical effects from the influence of the meteorology, simulations using numerical cloud models could be used.

Recently, Levin et al. (2005) incorporated aerosol properties that were measured in a dust storm over the eastern Mediterranean into the Tel Aviv University 2-D cloud model (Yin et al., 2000) and found that GCCN or enhanced IN concentration cause large modification in the total precipitation amounts from the cloud. They also showed that GCCN and IN change cloud dimensions (height and width) and modify the production of large droplets, graupel particles and ice crystals.

The main objective of this paper is to expand the work of Levin et al. (2005) by using many model simulations of different scenarios with the same cloud model for analyzing the impact of pollution and mineral dust aerosols on the development of clouds and precipitation in sub tropical cumulonimbus clouds, and to study their contribution to the changes in cloud height, cloud horizontal extent and cloud lifetime.

\section{The TAU-2D cloud model}

For the purpose of this study we used the Tel Aviv University 2-D numerical cloud model (TAU-2D) with detailed treatment of the cloud microphysics (Yin et al., 2000). This model uses the Spectral Method of Moments (Tzivion et al., 1987; Reisin et al., 1998) for calculating the growth of water drops and ice particles by various processes such as 
nucleation of water and ice, condensation, collection, riming, melting, drop breakup and sedimentation. The cloud is initiated with a short pulse of temperature and humidity just below cloud base. For the present study we used $300 \mathrm{~m}$ height and $300 \mathrm{~m}$ lateral resolutions and a $2 \mathrm{~s}$ time step.

It should be noted that Yin et al. (2002) performed a number of test runs with smaller grid space $(150 \times 150 \mathrm{~m}$ and $200 \times 200 \mathrm{~m}$ ) and did not find any significant sensitivity of the results to changes in grid resolution (except for a small delay in the cloud development). In order to save computer time so that many simulations could be performed, we chose to keep the $300 \mathrm{~m}$ resolution.

The initial conditions of the CCN vertical size distribution profiles and their chemical compositions for the Mediterranean clouds were set according to the airborne physical and chemical measurements reported by Levin et al. (2005). These measurements correspond to typical CCN size distribution profiles for the Mediterranean region during winter dust storms. Using the shape of the measured CCN size distributions the simulations were run with initial surface $\mathrm{CCN}$ concentrations that varied between $90 \mathrm{~cm}^{-3}$ (named "clean cloud") and $1350 \mathrm{~cm}^{-3}$ (named "polluted cloud"). The role of GCCN in clean and polluted conditions was also considered. In this study, GCCN were defined as aerosols larger than $0.5 \mu \mathrm{m}$ in diameter for the Mediterranean aerosol size distribution.

In the model, drops are nucleated based on the supersaturation and critical diameter following the classical Köhler theory (Pruppacher and Klett, 1997). Calculations of the critical radius for aerosol activation were done by assuming that $\mathrm{CCN}$ are composed of pure sea-salt $(\mathrm{NaCl})$ with $100 \%$ solubility. Sine cloud condensation nuclei begin to grow by absorption of water vapor long before they enter the cloud (e.g. Yin et al., 2000), these wetted particles provide the initial sizes for subsequent condensational growth. The main problem is how to include these wetted particles in the model calculations. In Yin et al. $(2000,2002)$ and here we used the method of Kogan (1991) that assumes that the initial droplet size formed on $\mathrm{CCN}$ with radii smaller than $0.12 \mu \mathrm{m}$ is equal to the equilibrium radius at $100 \% R H$, while for larger ones the initial radii are smaller by a factor $\mathrm{k}(\mathrm{r})$ than their equilibrium radii at $100 \% R H$ (see Yin et al. (2000) for further details). Once the drops reach their critical size or their size based on Kogan (1991) the drops are placed in the appropriate bin for subsequent growth.

The drops grow by condensation and then by collisioncoalescence processes. As the cloud develops vertically, reaching subfreezing temperatures, ice crystals begin to form by the freezing of cloud drops containing efficient IN, primarily those containing mineral particles. Ice nucleation is accounted for by using the parameterization of Meyers et al. (1992) in which the concentration of IN in the atmosphere is proportional to the supersaturation, when dealing with deposition or condensation-freezing processes, and proportional to the supercoolling temperature when dealing with contact nucleation. Ice particles also form through ice multiplication process induced by collisions of large drops and ice particles (Hallett and Mossop, 1974). The ice crystals grow by deposition and aggregation to form snow and by riming to form graupel particles. The large graupel particles and the large ice crystals eventually descend, melting on their way down to form raindrops. Large raindrops collide with other raindrops and break up to form smaller drops based on the algorithm of Reisin et al. (1998) and the distribution of Low and List (1982a, b).

For scenarios in which mineral dust particles enter the clouds we assumed that the concentration of IN increases by a factor of 10 above the values given by Meyers et al. (1992). Recently, DeMott et al. (2003) measured the IN concentrations in a dust layer that was transported from Africa to Florida. They showed that between about 1.5 and $4 \mathrm{~km}$ altitude the IN concentrations at $-38^{\circ} \mathrm{C}$ were about $1 \mathrm{~cm}^{-3}$. These values were about 20 to 100 times higher than those measured at lower altitudes in a non-dusty environment at the same location. Note that these measurements represent all the IN that nucleate ice down to $-38^{\circ} \mathrm{C}$. In the Mediterranean clouds simulated here the clouds only reached about $-30^{\circ} \mathrm{C}$, therefore the expected IN concentrations would be lower. Since there is no reliable data on the IN concentration in winter Mediterranean clouds we assumed that the concentration of IN increased by a factor of 10 above the clean background environmental values given by Meyers et al. (1992). This increase is used as an illustration of the potential effects of mineral dust on clouds and it could be modified if IN measurements in dust storms in this region become available.

A total of 20 scenarios were tested using the simulation for the Mediterranean conditions. Figure 1 shows the initial $\mathrm{CCN}$ size distribution on the ground used for the different cases. Figures $1 \mathrm{a}$ and $\mathrm{b}$ show the initial $\mathrm{CCN}$ size distributions for 10 of the cases used in the Mediterranean scenario without and with GCCN, respectively. The CCN size distributions in the cases with enhanced IN were the same as those shown in these figures. The different simulations represent a wide range of $\mathrm{CCN}$ concentrations beginning from extremely clean conditions with CCN concentrations of $90-100 \mathrm{~cm}^{-3}$ to extremely polluted conditions with $\mathrm{CCN}$ concentrations of $1350-1370 \mathrm{~cm}^{-3}$. The initial aerosol concentrations in all the cases remained constant from the surface to $1 \mathrm{~km}$ and then decreased exponentially with height with a decay factor of $2000 \mathrm{~m}$ (the concentrations decreased to $1 / \mathrm{e}$ of their values in $2000 \mathrm{~m}$ ).

The initial thermodynamic conditions for the simulations were selected to represent average sounding conditions of winter convective clouds in the eastern Mediterranean region. The temperatures at the sea surface and at cloud base (about $1000 \mathrm{~m}$ ) were $19^{\circ} \mathrm{C}$ and $7^{\circ} \mathrm{C}$, respectively. The humidity profile was similar to the profile presented by Yin et al. (2002) and is shown in Fig. 2. Wind shear was not included in the simulations discussed here. 


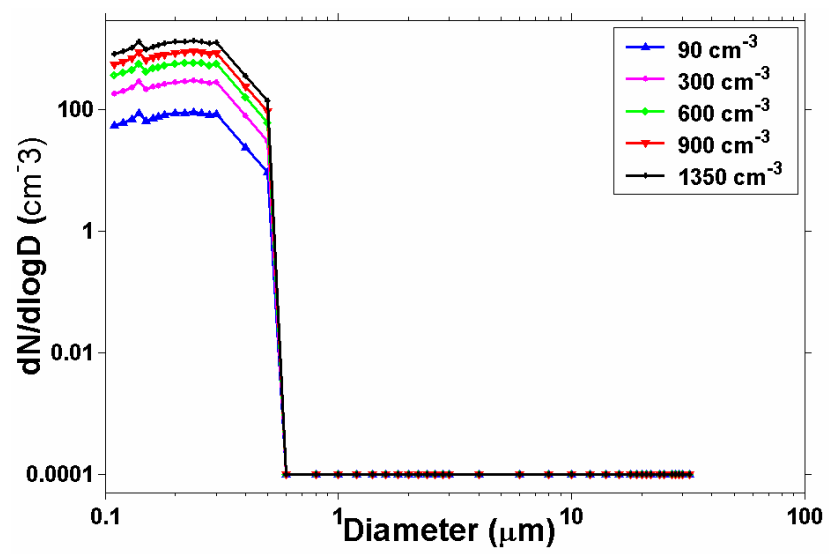

(a)

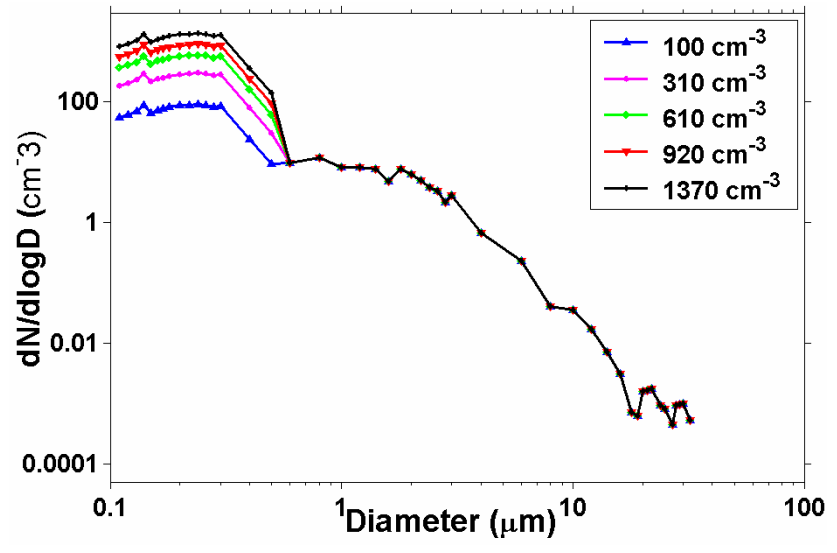

(b)

Fig. 1. Initial aerosol size distributions used in the TAU-2D cloud model, (a) and (b) correspond to cases in which GCCN are absent and present, respectively.

\section{Results}

The following discussion focuses on the effects of aerosols on four major features of clouds related to their size and precipitation production. These are: a) Total precipitation on the ground, b) Temporal evolution and spatial spreading of precipitation, c) Distribution of the hydrometeors within the cloud and d) Cloud dimensions (horizontal spreading and cloud top height) as function of time and its lifetime.

3.1 The effect of aerosols on the total precipitation on the ground

Figure 3 shows the total accumulated precipitation on the ground as a function of the initial CCN concentration for all the scenarios. Here, the total precipitation was defined as the total amount of water $\left(\mathrm{in} \mathrm{m}^{3}\right.$ ) reaching the ground for the entire simulation time. The model is two-dimensional; therefore, the total precipitation was calculated assuming that the cloud has a horizontal thickness of one kilometer.

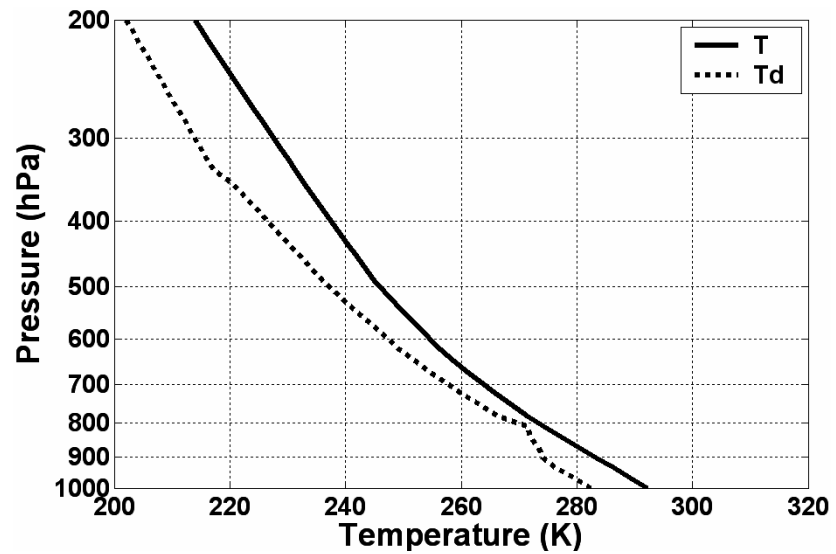

Fig. 2. Profile of initial thermodynamic conditions that were used in all the simulations.

Figure 3 reveals that as $\mathrm{CCN}$ concentration increases, or as the clouds become more polluted, the total precipitation decreases. For the reference scenarios in which no GCCN are added and IN concentrations remain as in Meyers et al. (1992), the clean cloud (with total CCN concentration of $90 \mathrm{~cm}^{-3}$ ) produced 16 times more precipitation than the polluted cloud $\left(1350 \mathrm{~cm}^{-3}\right)$.

The addition of very small amounts of GCCN (here between $10-20 \mathrm{~cm}^{-3}$ are added depending on the cloud type; corresponding to between about $1-10 \%$ of the background $\mathrm{CCN}$ concentrations) leads, in some cases, to increases in rainfall. (Please note that the initial $\mathrm{CCN}$ concentrations in the clean cloud and polluted cloud increased from 90 to 100 and from 1350 to 1370 , respectively, when GCCN were added.) Figure 3 shows that GCCN increase precipitation in the polluted clouds but have no effect on the clean clouds (while actually, their relative fraction is higher in the clean clouds). In fact the effects of the GCCN are not felt in a significant way in clouds with $\mathrm{CCN}$ concentrations smaller than about $600 \mathrm{~cm}^{-3}$. These increases are sometimes significant, especially in the polluted clouds, but they are small compared to the decrease in total rain when clean clouds become polluted. For example, a clean cloud with $300 \mathrm{CCN} \mathrm{cm}^{-3}$ reduces the total precipitation on the ground by a factor of four due to an increase in $\mathrm{CCN}$ to $900 \mathrm{~cm}^{-3}$. At the same time the addition of GCCN to the more polluted cloud will only enhance the rainfall by about $25 \%$. In other words, when dealing with meteorological conditions similar to those of the Mediterranean region, the effects on mixed phase clouds of pollution with or without GCCN is to decrease precipitation on the ground, while the GCCN helps to reduce this decrease somewhat.

The clouds that are developed with added IN produce ice more efficiently and deplete the cloud droplets. However, the simulation shows that under the same meteorological conditions these increases lead to a reduction in total rain amounts 
in all clouds except the most polluted ones where the effects are negligible.

The above results suggest that the addition of small concentrations of GCCN, such as sea salt or mineral dust particles coated with sea salt or sulfate (Levin et al., 1996; Levin et al., 2005) can reduce the magnitude of this rain suppression. On the other hand, enhancement of the IN concentration by the same mineral dust particles or by IN from anthropogenic sources suppresses the precipitation even more. We see, therefore, that GCCN and IN affect most clouds in the opposite direction.

3.2 The effects of aerosols on the temporal evolution and spatial spread of precipitation on the ground

In addition to the effects of the $\mathrm{CCN}, \mathrm{GCCN}$ and IN on the total accumulated precipitation, it is also instructive to look at their effects on the development of the precipitation rate on the ground and its spatial spread as function of time. Figure 4 shows the maximum precipitation rate on the ground as a function of time for the different cases and Fig. 5 shows contour plots of the spatial spreading of the precipitation rate on the ground as function of time. Figure 5a shows the effect of CCN population (without GCCN and IN enhancement) and Figs. $5 b$ and $c$ show the effects of added GCCN and IN enhancement for the clean and the polluted clouds, respectively. From Figs. 4 and 5 it is clear that the maximum precipitation rate is reached near cloud center.

Figure 4 shows that the times for the initiation of rain and the times to reach maximum precipitation rate are positively correlated to the $\mathrm{CCN}$ concentrations. In addition, the value of the maximum precipitation rate decreases as $\mathrm{CCN}$ concentrations increase.

Figure 5a shows the relationship between the $\mathrm{CCN}$ concentration and the spatial spreading of the precipitation for the reference cases in which neither GCCN nor enhanced IN concentration were added. The results reveal that precipitation from clean clouds spreads over larger area than from the heavy polluted clouds. Similar to Fig. 4, Fig. 5a also shows that precipitation starts earlier in clean clouds, beginning from a region near the main updraft, where vertical wind reaches its maximum value and then spreads toward the cloud edges. It is of great interest to note that in the cleanest cloud (with CCN concentration of $90 \mathrm{~cm}^{-3}$, see upper-left graph in Fig. 5a) the times of maximum precipitation rate and maximum spreading are not identical. In a more polluted cloud these times are approximately the same. This finding shows that in clean clouds the time to produce large raindrops by the microphysical processes is shorter than the time it takes for the cloud to spread over a large area. When the rain from the clean cloud reaches its maximum spread, the precipitation rate at the cloud center is very low (below $2 \mathrm{~mm} \mathrm{~h}^{-1}$ ). This means that at this stage most of the rain that developed at the cloud core has already reached the ground and the remaining small cloud droplets were trans-

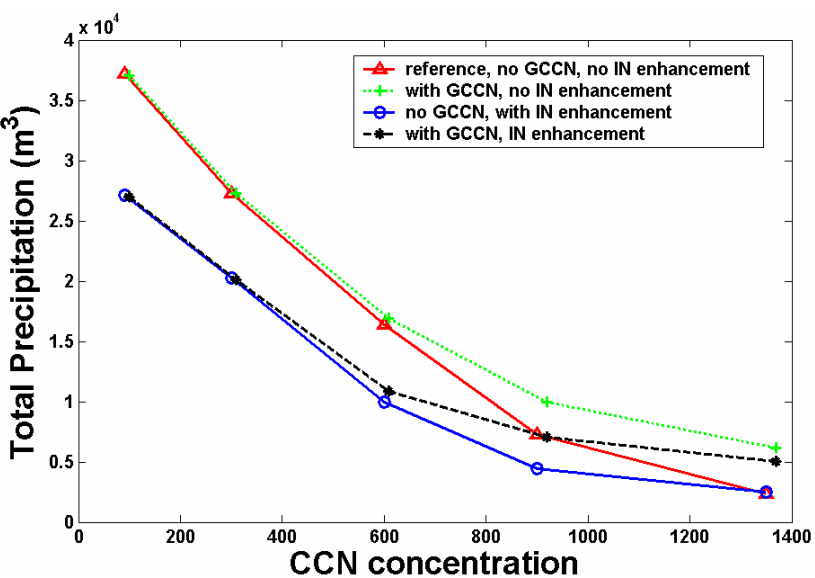

Fig. 3. Total precipitation on the ground produced by each case. Total precipitation was calculated by assuming cloud thickness of $1 \mathrm{~km}$.

ported closer to the cloud lateral boundaries during cloud development. The growth of the droplets at the cloud edges is limited due to the relatively low supersaturation and the lower concentrations of cloud drops. In the polluted cloud the droplets that are transported to the edges are too small to produce precipitation.

Adding GCCN to the initial CCN distribution has very little effect on the maximum precipitation rate (compare Figs. $4 \mathrm{a}$ and $\mathrm{b}$ or $4 \mathrm{c}$ and $\mathrm{d}$ ).

Figure $5 b$ shows that adding GCCN to the clean clouds has no effect on the spatial spreading or on the time of precipitation initiation. On the other hand, adding GCCN to the polluted cloud starts the rainfall earlier and increases the spatial spread of precipitation on the ground as compared to the reference case (Fig. 5c).

Comparison between Figs. $4 \mathrm{a}$ and $\mathrm{c}$ and Figs. $4 \mathrm{~b}$ and $\mathrm{d}$ shows that enhancement of IN concentration reduces the maximum precipitation rate in the cleaner clouds. IN enhancement has only minor effect on reducing the spatial spread of precipitation in the clean cloud (Fig. 5b) and has no effect on the spread of rainfall from polluted clouds (Fig. 5c).

\subsection{The effect of aerosols on the distribution of the hydrom- eteors within the cloud}

The effects of the aerosols on the precipitation efficiency and the spatial distribution of the hydrometeors in the cloud are demonstrated by calculating the mass content of each type of hydrometeor as a function of time. This is done by integrating the mass content over one dimension (horizontal or vertical) to obtain (in unit of $\mathrm{g} \mathrm{m}^{-2}$ ) liquid water path (LWP), ice path (IP), and graupel path (GP) as a function of time. As will be shown below, these calculations will serve to estimate the mass of water vapor and aerosols transported to the mid troposphere following cloud dissipation and will be used to illustrate the effects of aerosols on cloud dimensions. 


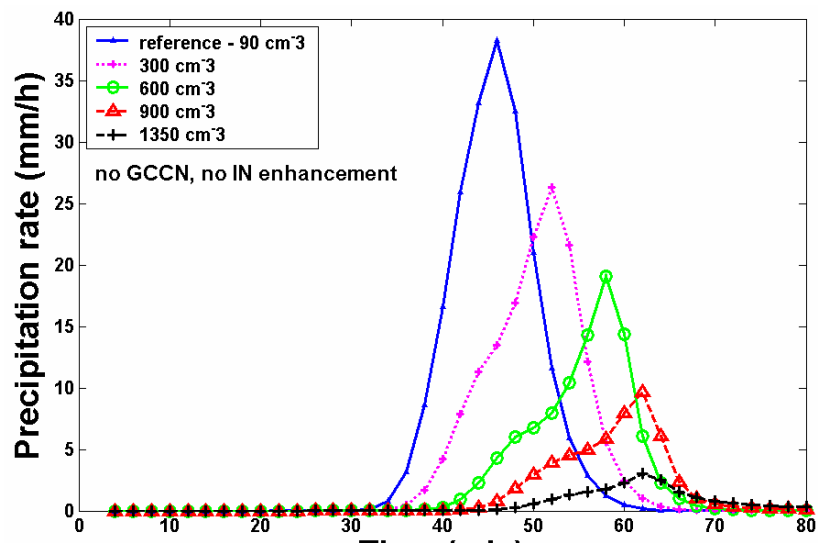

(a)

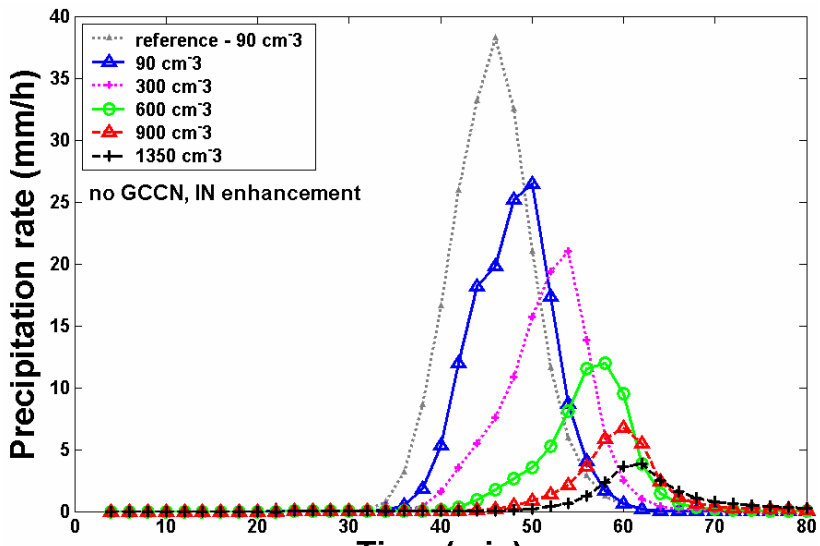

(c)

Time (min)

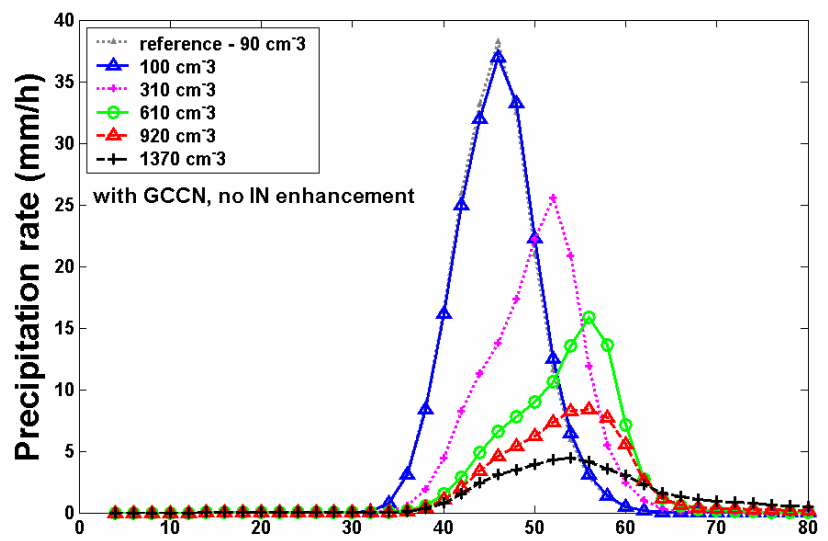

(b)

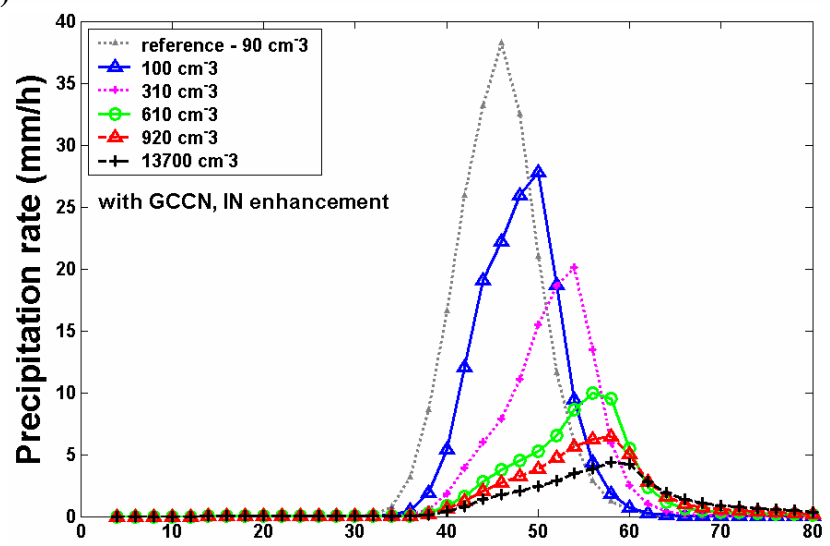

(d)

Time (min)

Fig. 4. Precipitation rate as function of time for the entire cases. (a) corresponds to cases in which GCCN are not present and IN concentration is not enhanced, (b) corresponds to cases in which GCCN are added and IN concentration is not enhanced, (c) corresponds to cases in which GCCN are not present and IN concentration is enhanced, (d) corresponds to cases in which GCCN added and IN concentration is enhanced.

The water, ice and graupel paths of mass content (in $\mathrm{g} \mathrm{m}^{-2}$ ) in the clouds as a function of time, height and width are shown in Figs. 6-10. The upper two panels in each of these figures represent the vertical integral of the mixing ratio of each type of hydrometeor as a function of time and horizontal location. The lower two panels represent the vertical distribution of the mixing ratio of the different hydrometeors integrated over the horizontal axis (units of $\mathrm{g} \mathrm{m}^{-2}$ ) as a function of time.

Figures 6a and $b$ reveal that the GP in the polluted cloud is much lower than in the clean cloud. Figure $6 \mathrm{c}$ and $\mathrm{d}$ further show that the spatial spread of the graupel is much smaller, located between about $5000 \mathrm{~m}$ down to about $2000 \mathrm{~m}$ in the polluted cloud compared to spread between about $6000 \mathrm{~m}$ down to the surface in the clean cloud. Graupel particles first appear around $25 \mathrm{~min}$ and $6000 \mathrm{~m}$ in the clean cloud while they begin to form around $35 \mathrm{~min}$ and 5000 in the polluted cloud (see Fig. $6 \mathrm{c}$ and d). The delay in the formation of the graupel particles in the polluted cloud is a result of the low freezing efficiency of the smaller cloud drops in this cloud.
Since the graupel particles do not grow fast, the droplets reach higher altitudes and form more ice crystals.

As can be seen in Fig. 6, the IP is much higher in the polluted cloud and it spreads over much larger vertical extend; all the way from about $7000 \mathrm{~m}$ down to $2000 \mathrm{~m}$. In the polluted cloud as compared to the clean cloud the value of the LWP is slightly smaller, it spreads over slightly larger volume and the drops reach higher altitudes (compare Figs. 6c and d). These figures also show that the height of maximum LWP starts to descend earlier in the clean cloud (at about $28 \mathrm{~min}$ ) as compared to $32 \mathrm{~min}$ and to a slower descend in the polluted cloud. The above behavior is associated with the fact that the precipitation starts earlier (around $35 \mathrm{~min}$ ) and lasts longer (it end on around $57 \mathrm{~min}$ ) in the clean cloud. In contrast, the polluted cloud starts precipitating only after about $50 \mathrm{~min}$ and lasts only until about $67 \mathrm{~min}$.

Some of the precipitation in the clean cloud is formed by graupel particles (in spite of some melting, some graupel reach the ground), while in the polluted clouds the amount of rain is small and is mainly formed by raindrops. One other 

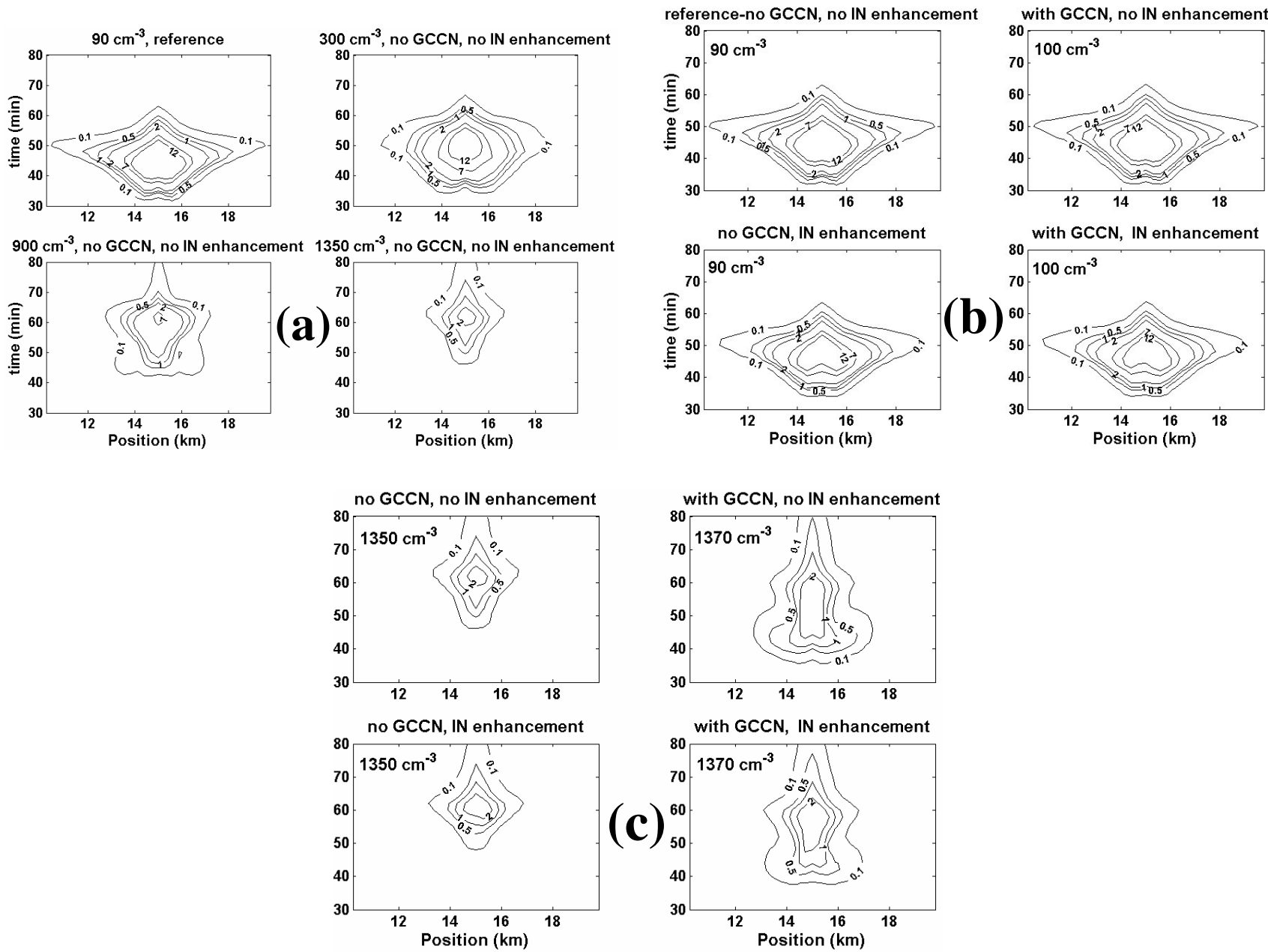

Fig. 5. Precipitation rate on the ground as function of time. (a) effect of CCN concentration when no GCCN are present and no IN enhancement, (b) Clean cloud with GCCN and no IN enhancement (upper right), no GCCN and with IN enhancement (lower left) and with both GCCN and IN (lower right) (c) like (b) except for a polluted cloud.

feature that clearly appears in Figs. $6 \mathrm{a}$ and $\mathrm{b}$ is the larger horizontal extent of the polluted cloud (about 1 to $1.5 \mathrm{~km}$ higher than the clean cloud) and the higher cloud top (about 0.5$1 \mathrm{~km}$ higher than the clean cloud).

The effects of GCCN on the development of clean and polluted clouds are shown in Figs. 7 and 9, respectively. In these cases only 10 and $20 \mathrm{~cm}^{-3}$ GCCN were added to the background $\mathrm{CCN}$ of the clean and polluted clouds, respectively. As can be seen hardly any difference can be detected in the clean clouds while the effects on the polluted cloud are significant. Although larger drops are produced when GCCN are present, the biggest effect is in the production of graupel particles (compare Figs. 9a and b). Once GCCN are active in the polluted cloud the graupel particles begin to form around $30 \mathrm{~min}$ (Fig. 9a) and at an altitude of $5500 \mathrm{~m}$, about $5 \mathrm{~min}$ earlier than in cloud with no GCCN. The larger drops formed due to the existence of the GCCN enhance the probability of freezing and increases the riming efficiency; both leading to more graupel mass and enhanced precipitation on the ground (compare the contours at the lower altitudes on Figs. 9c and d). These figures also show that precipitation starts earlier and lasts much longer. The enhanced graupel production is responsible for the increase in precipitation shown in Fig. 3 (the difference between the curve with and without GCCN).

The effects of added IN on the clean and polluted clouds is shown in Figs. 8 and 10, respectively. Figure 8 shows that the amount of rainfall slightly decreases due to the added IN while the amount of ice crystals aloft increases. The additional IN lead to the formation of more ice crystals by depleting some of the cloud drops (note the small reduction in the LWC). The enhancement of small ice crystals in the upper parts of the cloud leads to the formation of an anvil and to a large horizontal spread of the cloud mass as can be seen by comparing Fig. $8 \mathrm{a}$ and $\mathrm{b}$ for times greater than $50 \mathrm{~min}$. 

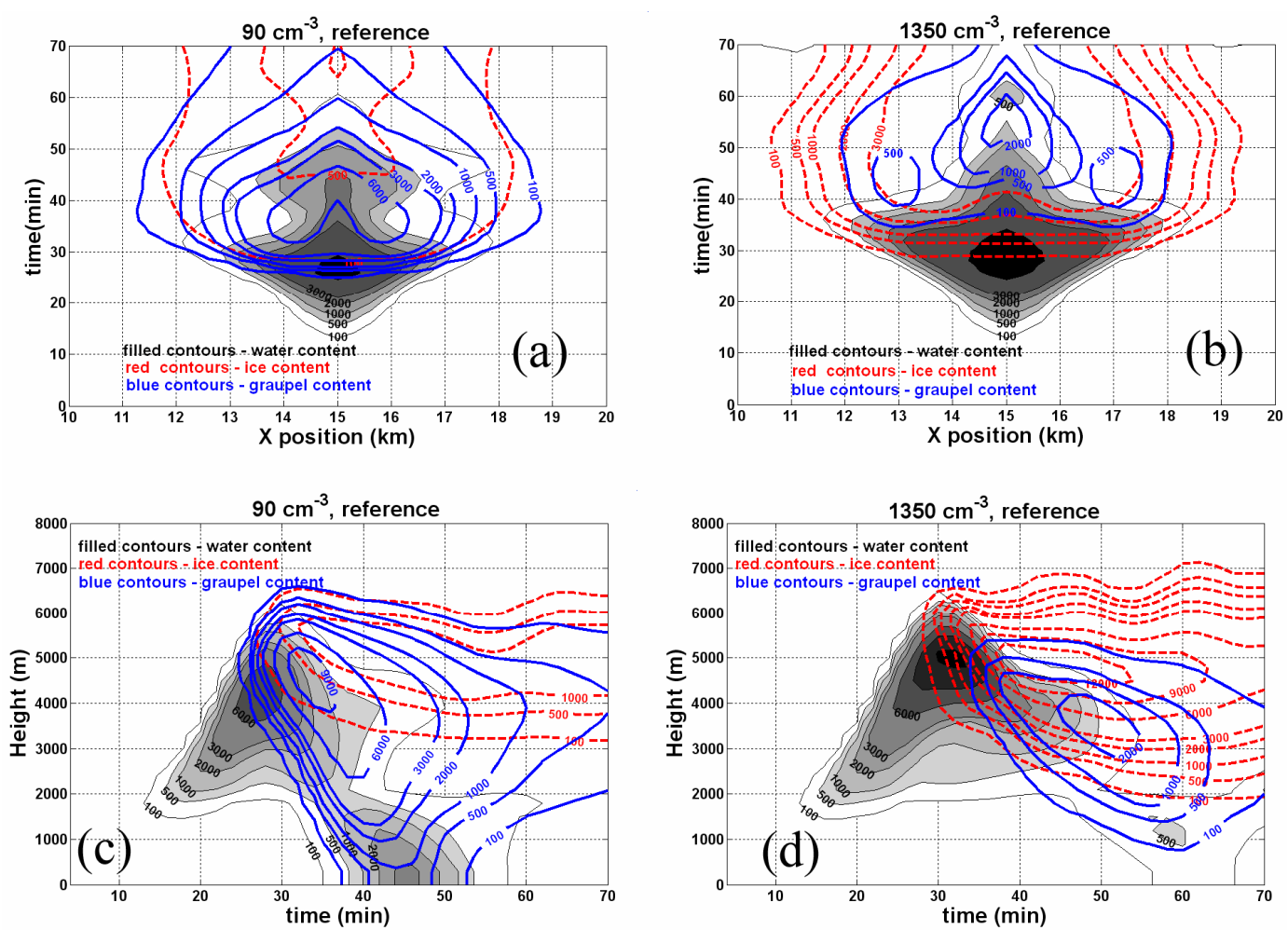

Fig. 6. Water, ice and graupel paths of mass content (in $\mathrm{g} \mathrm{m}^{-2}$ ) in the clouds as a function of time, height and width. no GCCN were added and IN concentration are not enhanced. (a) and (b) - Vertical integral of the mixing ratio of each type of hydrometeor as a function of time and horizontal location for the clean cloud and the polluted cloud respectively. (c) and (d) - Vertical distribution of the mixing ratio of the different hydrometeors integrated over the horizontal axis $\left(\mathrm{g} \mathrm{m}^{-2}\right)$ as a function of time for the clean and the polluted clouds respectively.

Figures 10a and $\mathrm{b}$ for the polluted cloud shows that the enhanced IN reduces the GP, especially at regions near its edges. Large amounts of ice crystals appear earlier in the cloud when IN is enhanced ( $25 \mathrm{~min}$ as in Fig. 10d compared to $30 \mathrm{~min}$ in Fig. 10c). On the other hand, the effect on precipitation on the ground is negligible.

Integrating the total mass in the cloud over time allows us to estimate the amount of water that can be evaporated back into the atmosphere after the rain stops. Figure 11 compares the total mass content as a function of time in the clean and polluted clouds. It shows that the conversion from vapor to hydrometeors is more efficient in the clean cloud since the total hydrometeor mass reaches its maximum earlier. However, the maximum total mass in both clouds is only different by $<10 \%$, suggesting that the total mass is not strongly affected by the $\mathrm{CCN}$ concentrations. Of course the rate of hydrometeor formation is certainly different (see Fig. 11). The CCN concentrations affect the remaining mass in the cloud after the clouds stopped raining. While in the clean clouds most of the mass of the cloud disappears (mostly by rainfall), in the polluted cloud most of the mass remains above the ground. Evaporation of the drops and especially melting and evaporation of the ice crystals (Fig. 6d) after cloud dissipation leads to higher aerosol concentrations and higher water vapor mass in the upper regions of the troposphere. This may be signifi- cant when evaluating the effects of aerosols and water vapor on global radiative forcing.

3.4 The effects of aerosols on cloud's dimensions and lifetime

Figure 6 shows that the horizontal extend of the polluted cloud is larger by as much as $1 \mathrm{~km}$ than the clean cloud. The depths of the polluted cloud are also bigger, but to a much lesser extend (only about 200-500 m). Comparison between Fig. $6 \mathrm{c}$ and $\mathrm{d}$ also shows that while both clean and polluted clouds begin their growth at the same time (about $15 \mathrm{~min}$ from the start of the simulation), the polluted cloud lives longer, leaving more mass after precipitation stops (see also Fig. 11). The slow rate of growth and the smaller depletion of water by precipitation due to the smaller sizes of the droplets and graupel particles in the polluted cloud explain the longer lifetime of these clouds.

The addition of GCCN to the polluted cloud modifies the relative contents of water and graupel (see Figs. 9c and d after $30 \mathrm{~min}$ ) but the effect on the cloud top height (considering all types of hydrometeors) is minimal. It is interesting to note that between 30-40 min most the mass at the upper regions of the polluted cloud (above $5000 \mathrm{~m}$ ) contain water and ice while added GCCN convert some of the water to graupel. On 

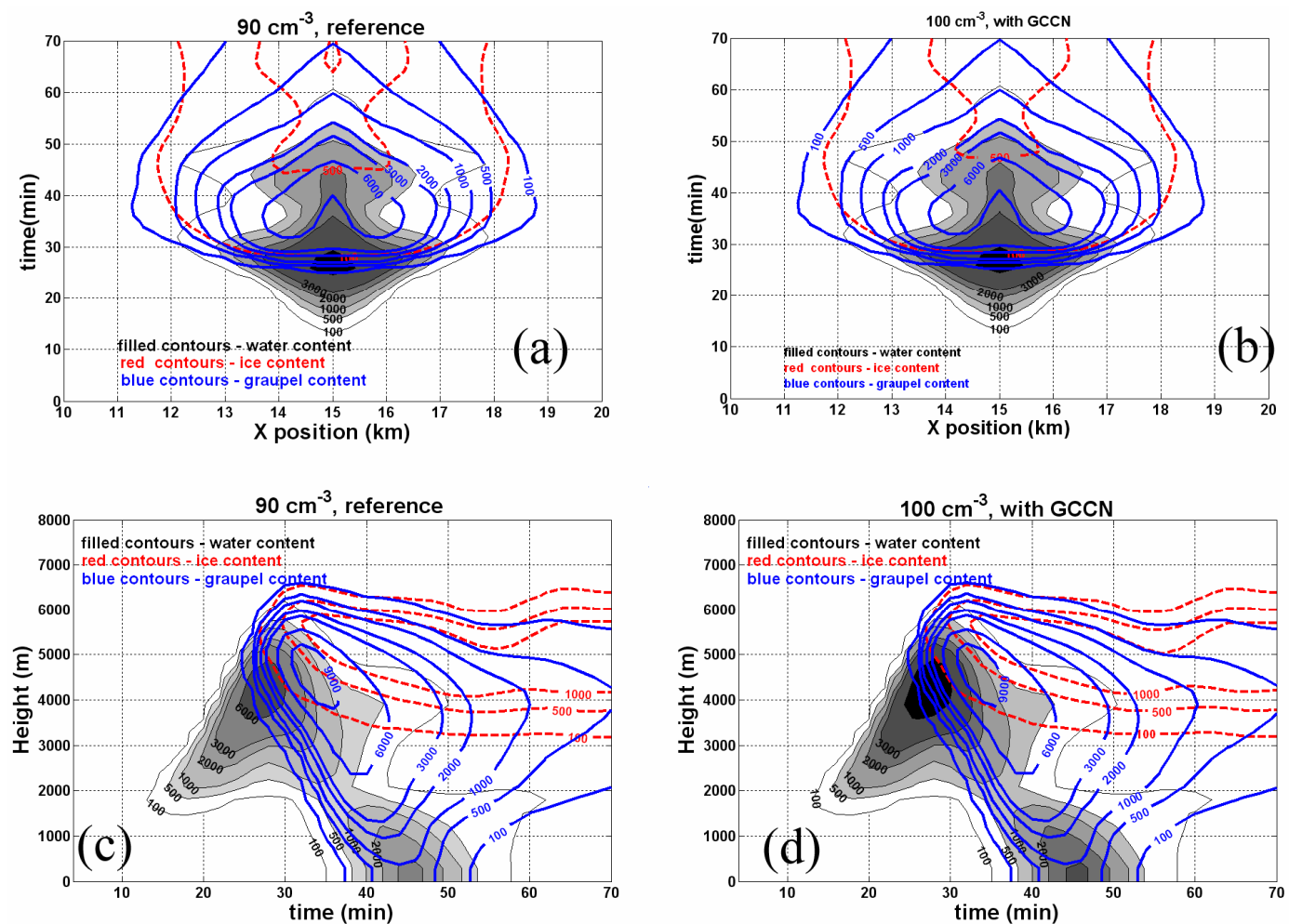

Fig. 7. Water, ice and graupel paths of mass content (in $\mathrm{g} \mathrm{m}^{-2}$ ) in the clean clouds as a function of time, height and width. (a) and (b) Vertical integral of the mixing ratio of each type of hydrometeor as a function of time and horizontal location for clouds without and with GCCN respectively. (c) and (d) - Vertical distribution of the mixing ratio of the different hydrometeors integrated over the horizontal axis $\left(\mathrm{g} \mathrm{m}^{-2}\right)$ as a function of time for the clouds without and with GCCN, respectively.

the other hand there is no noticeable effect of GCCN on the height of the clean cloud. Figures 7 and 9 also show that adding GCCN to a polluted cloud has almost no influence on the cloud lifetime although in polluted clouds rainfall is greater when GCCN are added.

The addition of IN to clean clouds increases the ice content near cloud top and slightly increases its height (compare Figs. $8 \mathrm{c}$ and d). The added ice crystals at the upper reaches of these clouds also increases cloud horizontal extent (Figs. 8a and $b$ ). On the other hand, the addition of IN to the heavily polluted cloud only slightly increases cloud top height and width (see Figs. 10c and d) and does not have an effect on its lifetime (see Figs. 8 and 10).

\section{Discussion}

4.1 The effects of CCN concentration, GCCN and IN on rainfall

Figure 3 shows that under the same meteorological conditions polluted clouds precipitate less than clean clouds. In fact, increasing the $\mathrm{CCN}$ concentrations from 300 to $900 \mathrm{~cm}^{-3}$ decreases the total amount of rain on the ground by a factor of about 3.7. Incorporating small numbers of
GCCN in the CCN spectrum increases the total rainfall on the ground but does not compensate for the large decrease due to the increases in $\mathrm{CCN}$ by pollution. Enhancing IN activity in the clouds simulated here reduces the total precipitation on the ground in all clouds except in the heavy polluted cases.

Furthermore, the results show that adding GCCN and enhancing IN activity not only affect the total precipitation on the ground (Fig. 3) but also modify the precipitation rates (Fig. 4) and the spatial spread of the precipitation (Fig. 5), while influencing relatively little $(<10 \%)$ the maximum total masses of water and ice (Fig. 11).

These results imply that the thermodynamic conditions determine the "potential" maximum total mass of the cloud (Fig. 11), but the distributions of water, graupel and ice hydrometeors during the cloud lifetime and the amount of precipitation are determined by the cloud microphysical processes (Figs. 6-10). These processes are influenced by the characteristics of the $\mathrm{CCN}$ and the IN population that enter the cloud at the beginning and during its growth.

A more careful view of the microphysical processes reveals that the insertion of small concentrations of GCCN affects differently the production of precipitation in clean and the polluted clouds. Supersaturation reaches higher values 

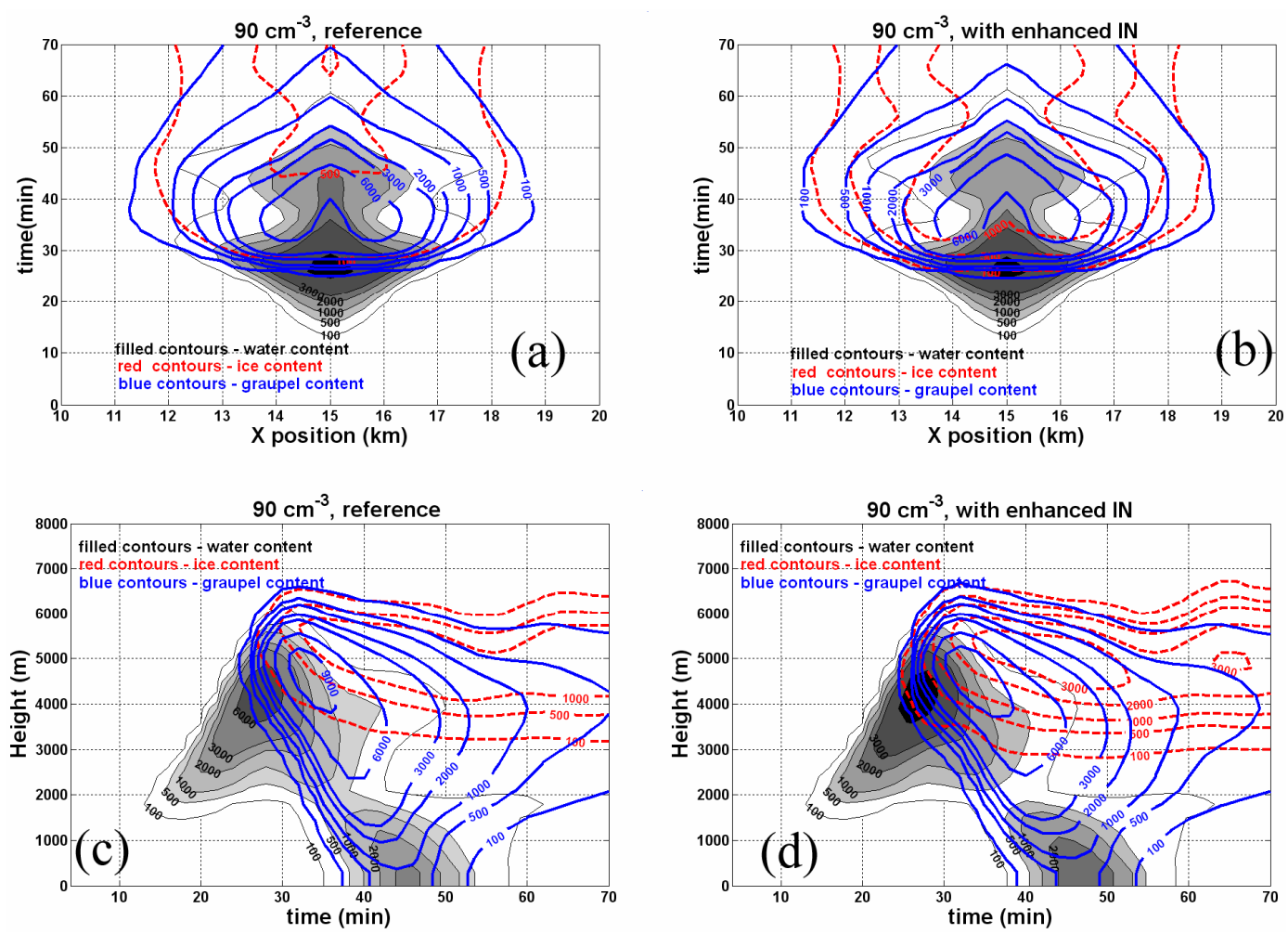

Fig. 8. Water, ice and graupel paths of mass content (in $\mathrm{g} \mathrm{m}^{-2}$ ) in the clean clouds as a function of time, height and width. (a) and (b) Vertical integral of the mixing ratio of each type of hydrometeor as a function of time and horizontal location for clouds without and with IN enhancement respectively. (c) and (d) - Vertical distribution of the mixing ratio of the different hydrometeors integrated over the horizontal axis $\left(\mathrm{g} \mathrm{m}^{-2}\right)$ as a function of time for the clouds without and with IN enhancement, respectively.

in clean clouds because the small concentrations of droplets are not sufficient to rapidly deplete the access water vapor. The appearance of higher supersaturation in clean clouds, therefore, leads to faster growth by condensation of each droplet and to an earlier and faster growth by coalescence. The addition of a few (about $5-10 \%$ by number) GCCN to clean clouds does not accelerate the already rapid growth process. In the polluted clouds, on the other hand, the addition of similar concentrations of GCCN (only about $1.5 \%$ by number) creates a few relatively large droplets (with radii $>20 \mu \mathrm{m}$ ) that grow rapidly by collecting smaller droplets. Subsequently and at higher altitudes, these large droplets are among the first to freeze and produce graupel particles (Figs. 9c and d). These different responses of the polluted and clean clouds to the addition of GCCN are seen in Fig. 3, where no effects on precipitation amounts are observed in the clean clouds but significant enhancement effects are obtained in the polluted cloud.

When GCCN are missing from the $\mathrm{CCN}$ population, graupel production is limited because there are not many large droplets to freeze. Under these conditions high values of supersaturation with respect to ice develop and high concentrations of IN are activated. In our model, small frozen droplets become graupel particles only when their radii are larger than
$100 \mu \mathrm{m}$. Therefore, in the absence of large droplets, the riming efficiency remains low and the ice crystals remain small (as was shown by Borys et al., 2003).

When the CCN spectrum contains GCCN, larger cloud droplets are formed at lower altitudes leading to an earlier formation of graupel particles (Fig. 9d). The reason more graupel particles are formed is because the larger unfrozen drops have higher riming efficiency with ice crystals. In addition, the larger drops have higher a probability to freeze.

Unlike the effects of the GCCN, increases in the IN concentrations affect differently the clean and polluted clouds. In clean clouds, GCCN do not contribute significantly to the production of graupel particles (Fig. 7). However, when more IN are present, the ice concentration increases at the expense of the water drops, which are the main source for the growth by riming. The enhancement of IN leads to lower water content, lower graupel mass loading and higher ice content (Fig. 8). In the polluted clouds, enhancement of IN concentrations seems to have only a minor effect on the total precipitation. This is because high concentrations of small droplets climb to high altitudes before they become large enough to rime with ice crystals and to form graupel particles. Figure 3 summarizes this by showing that as CCN concentrations increase, the reduction in rainfall due to the 

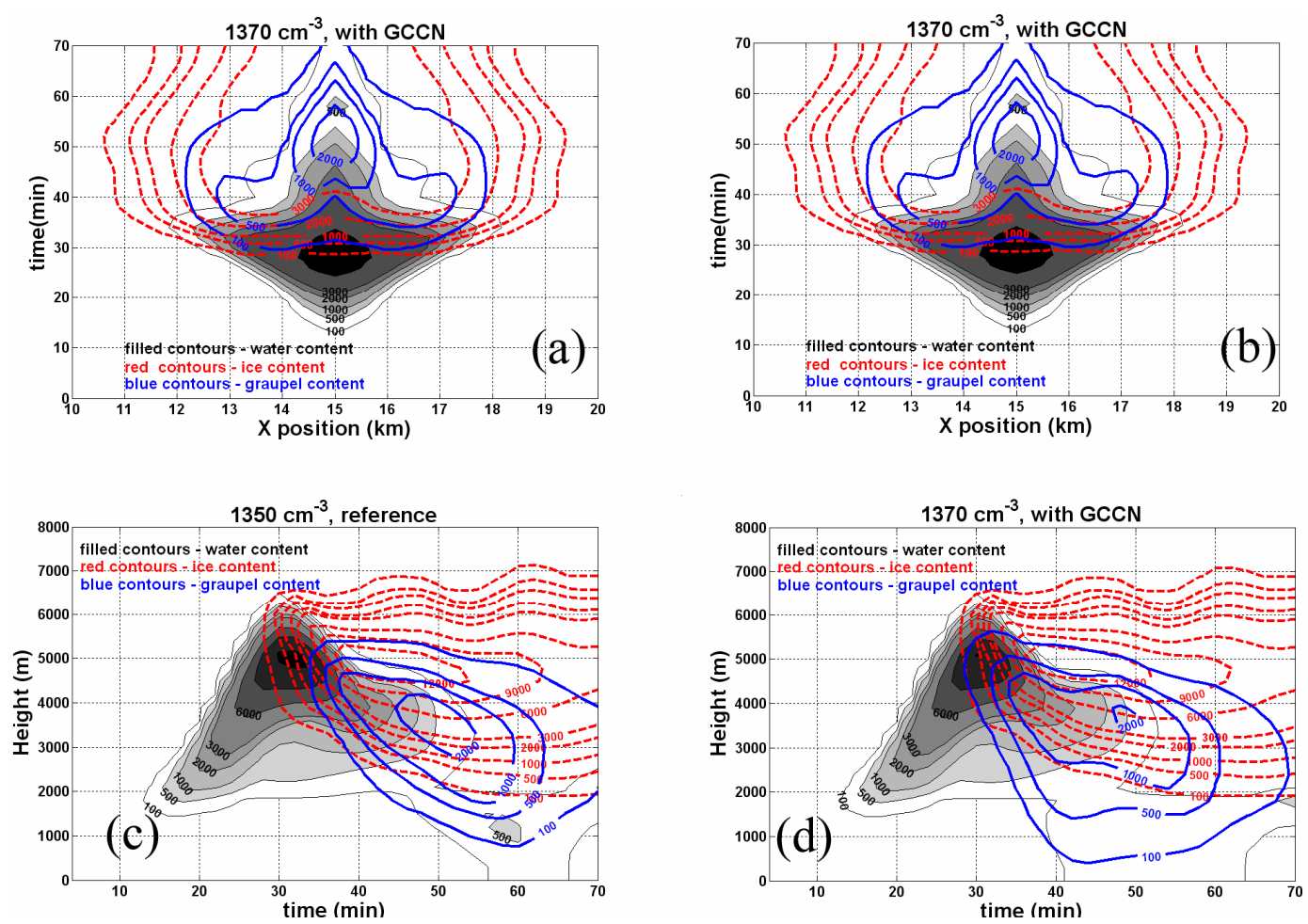

Fig. 9. Water, ice and graupel paths of mass content (in $\mathrm{g} \mathrm{m}^{-2}$ ) in the polluted clouds as a function of time, height and width. (a) and (b) - Vertical integral of the mixing ratio of each type of hydrometeor as a function of time and horizontal location for clouds without and with GCCN respectively. (c) and (d) - Vertical distribution of the mixing ratio of the different hydrometeors integrated over the horizontal axis $\left(\mathrm{g} \mathrm{m}^{-2}\right)$ as a function of time for the clouds without and with GCCN, respectively.

enhanced IN concentration diminishes. Comparison between Figs. $4 \mathrm{a}$ and $\mathrm{c}$ also shows that while IN enhancement causes precipitation to start later in clean clouds, it does not have a significant effect on the polluted ones.

Similar results about the effect of $\mathrm{CCN}$ concentration on cloud rainfall efficiency were found in a number of numerical studies (Reisin et al., 1996, 1998; Phillips et al., 2001; Khain et al., 2004; Khain and Pokrovsky, 2004) but only in relatively few observational studies (Warner and Twomey, 1967; Rosenfeld et al., 2000; Givati and Rosenfeld, 2004).

The above results also support the previous studies on the effects of GCCN on precipitation (e.g. Johnson et al., 1982; Feingold et al., 1999; Yin et al., 2002; Rosenfeld et al., 2002; Rudich et al., 2002). The results here show that inclusion of GCCN in the CCN population enhances precipitation only when $\mathrm{CCN}$ concentrations are high. These results suggest that large aerosols that can act as $\mathrm{CCN}$ such as sea salt and mineral dust coated with soluble material may have a positive effect only in highly polluted regions. Although the absolute amounts of rain from such polluted clouds are low, the relative increases due to the effects of GCCN could be high.

From the discussion above it becomes clear that in terms of total rainfall on the ground, increasing the concentrations of both GCCN and IN seem to have opposing ef- fects. GCCN tend to increase precipitation, primarily in the polluted clouds, while added IN decreases precipitation amounts, but mainly in the clean clouds.

\subsection{The effects on cloud dimensions and lifetime}

The results of the simulations also shed light on the role of aerosols in modifying the cloud dimensions and lifetime. These features have received much attention recently due to their effect on the earth radiation budget as characterized by the various global aerosols indirect effects (e.g. Lohman and Feichter, 2005).

Figure 6 demonstrates that polluted clouds climb to higher altitudes than clean ones. The initial CCN concentrations affect the size and types of hydrometeors that reach the cold regions of the cloud and thus may change cloud top height and width. Figures $6 \mathrm{a}$ and $\mathrm{b}$ show that the largest spread of the cloud occurs at the upper regions (where graupel and ice are present). In the polluted clouds many small droplets reach the higher levels with sizes that are insufficient to fall down against the updrafts. Because of their small size these droplets have low riming efficiencies with existing graupel or ice particles, thus preventing the latter from growing. At the same time, these small droplets can form ice crystals by immersion or by contact freezing and increase the 

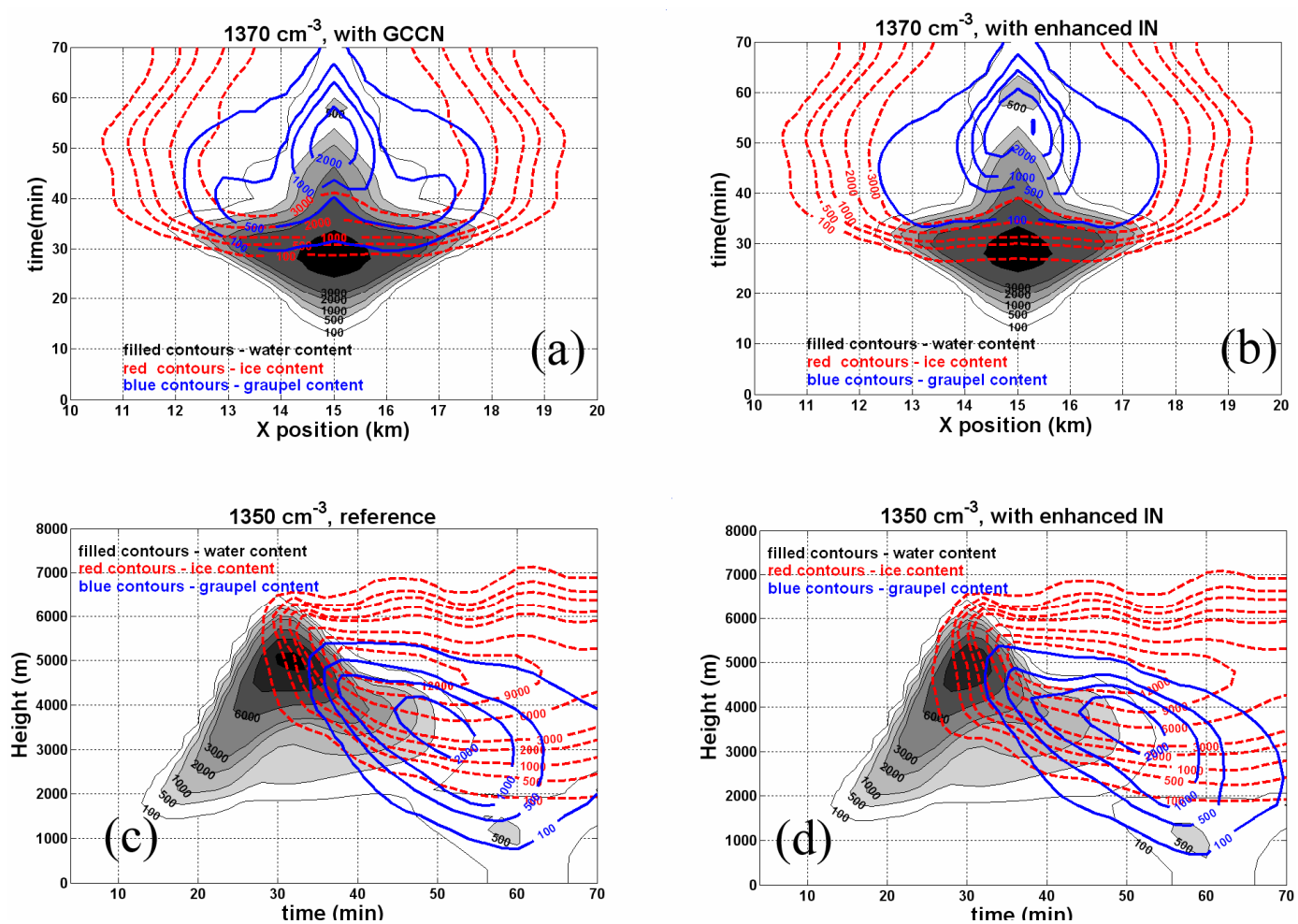

Fig. 10. Water, ice and graupel paths of mass content (in $\mathrm{g} \mathrm{m}^{-2}$ ) in the polluted clouds as a function of time, height and width. (a) and (b) Vertical integral of the mixing ratio of each type of hydrometeor as a function of time and horizontal location for clouds without and with IN enhancement respectively. (c) and (d) - Vertical distribution of the mixing ratio of the different hydrometeors integrated over the horizontal axis $\left(\mathrm{g} \mathrm{m}^{-2}\right)$ as a function of time for the clouds without and with IN enhancement, respectively.

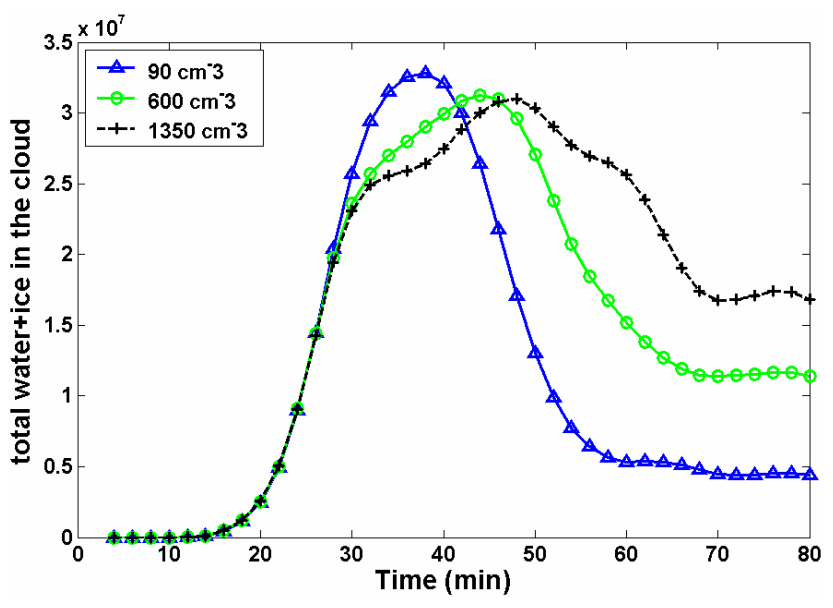

Fig. 11. The effect of CCN concentration on the total mass of water, ice and graupels as a function of time.

ice crystal concentrations in the upper reaches of the cloud (Fig. 6d). When the cloud stops precipitating these crystals simply evaporate releasing water vapor and aerosols to the upper regions of the troposphere. From Fig. 11a one can surmise that about 3.5 times higher cloud mass is left behind in the mid troposphere after precipitation stops from a polluted cloud than from a clean one (while the differences between the maximum masses of the polluted and clean clouds during their growth are only about $10 \%$ ). This water mass usually evaporates and modifies the vertical profile of humidity. In other words, polluted clouds are efficient vehicle for transporting water vapor from lower levels to the mid and upper troposphere.

The presence of GCCN increases the drop size of a few drops and accelerates their growth. This leads to an increase in the mass loading of drops and graupel. However, since the number of such large particles is relatively small, the effect on cloud top height is very small. IN enhancement in polluted clouds, on the other hand, reduces the rate of graupel production but increases the ice mass in the upper parts of the cloud. These opposite tendencies account for the similar dimensions of the heavy polluted cloud $\left(1350 \mathrm{~cm}^{-3}\right)$ with or without enhanced IN. 


\section{Summary and conclusions}

The Tel Aviv University 2-D cloud model was used to describe the links between aerosol concentration, cloud growth processes and precipitation. It is shown that under the same meteorological conditions different aerosol populations can significantly modify total precipitation, cloud coverage and cloud life-time by affecting only the cloud microphysical processes.

In order to separate the influence of meteorology from those of the aerosol-cloud microphysical effects, a single atmospheric thermodynamic profile was used in all the different scenarios. This profile represents typical winter conditions in the Mediterranean region.

The most important findings are the following:

- Under the same meteorological conditions, polluted clouds produce less precipitation, the initiation of precipitation is delayed and the lifetime of the clouds is longer.

- A reduction by a factor of about 3.7 in total rain amounts on the ground is seen by increasing $\mathrm{CCN}$ concentrations from 300 to $900 \mathrm{~cm}^{-3}$.

- GCCN enhances the total precipitation on the ground in polluted (or continental with $\mathrm{CCN}$ concentrations $>600 \mathrm{~cm}^{-3}$ ) clouds but it has no noticeable effect on cleaner clouds.

- The increased rainfall due to GCCN is mainly due to the increase in the amount of graupel in the cloud.

- The increase in rainfall due to GCCN is small in comparison to the decrease in precipitation due to pollution.

- Adding more effective and high concentrations of IN (such as dust particles) reduces the total amount of precipitation on the ground. This reduction is more pronounced in clean clouds than in polluted ones.

- Polluted clouds and those affected by higher concentrations of IN lead to wider clouds (anvils). This could explain the satellite observation of higher cloud fraction under high aerosol content.

- Polluted clouds have higher cloud tops than clean clouds.

- Since much of the cloud mass near cloud tops evaporates after the cloud stops raining, more water vapor is released into the mid troposphere from polluted clouds than from clean ones. Using the model simulations we obtained a value of about 3.5 for the ratio of the amount of cloud mass that evaporates from a polluted cloud to a clean one. This means that much water vapor is transported from lower levels to the mid troposphere under polluted conditions.
Since the results have implications for climate study and for water resources, it should be expanded to include tropical and fair weather clouds.

Acknowledgements. Part of this work was carried out while Z. Levin was on sabbatical at NASA Goddard Space Flight Center under the UMBC-NASA GEST program. The authors thank Y. Kaufman, L. Remer and I. Koren from NASA Goddard for many constructive discussions about interpretation of aerosol-cloud interactions from model simulations and remote sensing measurements. This study was supported by the United States - Israel Binational Science Foundation (grant No. 2000308) and the Israeli Ministry of Science (grant No. 01-01-01464).

Edited by: K. Carslaw

\section{References}

Ackerman, A. S., Toon, O. B., Stevens, D. E., Heymsfield, A. J., Ramanathan, V., and Welton, E. J.: Reduction of tropical cloudiness by soot, Science, 288, 1042-1047, 2000.

Albrecht, B.: Aerosols, cloud microphysics, and fractional cloudiness, Science, 245, 1227-1230, 1989.

Ayers, G. P.: Air pollution and climate change: has air pollution suppressed rainfall over Australia?, Clean Air \& Environ. Quality, 39(2), 51-57, 2005.

Borys, R. D., Lowenthal, D. H., Cohn, S. A., and Brown, W. O. J.: Mountaintop and radar measurements of anthropogenic aerosol effects on snow growth and snowfall rate, Geophys. Res. Lett., 30(10), 1538, doi:10.1029/2002GL016855, 2003.

DeMott, P. J., Sassen, K., Poellet, M. R., Baumgardner, D., Rogers, D. C., Brooks, S. D., Prenni, A. J., and Kreidenweis, S. M.: African dust aerosols as atmospheric ice nuclei, Geophys. Res. Lett. 30(14), 1732, doi:10.1029/2003GL017410, 2003.

Feingold, G., Cotton, W. R., Kreidenweis, S. M., and Davis, J. T.: Impact of giant Cloud Condensation Nuclei on drizzle formation in marine stratocumulus: Implications for cloud radiative properties, J. Atmos. Sci., 56, 4100-4117, 1999.

Givati, A. and Rosenfeld, D.: Quantifying precipitation suppression due to air pollution, J. App. Meteor., 43, 1038-1056, 2004.

Hallett, J. and Mossop, S. C.: Production of secondary ice crystals during the riming process, Nature, 249, 26-28, 1974.

Hindman II, E. E., Hobbs, P. V., and Radke, L. F.: Cloud Condensation Nuclei from a paper mill. Part I: Measured effect on clouds, J. Appl. Meteor., 16, 745-752, 1977a.

Hindman II, E. E., Tag, P. M., Silverman, B. A., and Hobbs, P. V.: Cloud Condensation Nuclei from a paper mill, Part II: Calculated effects on rainfall, J. Appl. Meteor., 16, 753-755, 1977 b.

Hobbs, P. V., Radke, L. F., and Shumway, S. E.: Cloud Condensation Nuclei from industrial sources and their apparent influence on precipitation in Washington state, J. Atmos. Sci., 27(1), 8189, 1970.

Johnson, D. B.: The role of giant and ultragiant aerosol particles in warm rain initiation, J. Atmos. Sci., 39, 448-460, 1982.

Khain, A., Pokrovsky, A., Pinsky, M., Seifert, A., and Phillips, V.: Simulation of effects of atmospheric aerosols on deep turbulent convective clouds using a spectral micro-physics mixed-phase cumulus cloud model. Part 1: model description and possible applications, J. Atmos. Sci., 61, 2963-2982, 2004. 
Khain, A. and Pokrovsky, A.: Simulation of effects of atmospheric aerosols on deep turbulent convective clouds using a spectral micro-physics mixed-phase cumulus cloud model. Part 2: sensitivity study, J. Atmos. Sci., 61, 2983-3001, 2004.

Kaufman, Y. J., Koren, I., Remer, L. A., Rosenfeld, D., and Rudich, Y.: The Effect of smoke, dust and pollution aerosol on shallow cloud development over the Atlantic Ocean, Proc. Natl. Acad. Soc. USA, 102, 32, 11 207-11 212, 2005.

Kogan, Y. L.: The simulation of a convective cloud in a 3-D model with explicit microphysics: Part I. Model description and sensitivity experiments, J. Atmos. Sci. 48, 1160-1189, 1991.

Koren I., Kaufman, Y. J., Rosenfeld, D., Remer, L. A., and Rudich Y.: Aerosol invigoration and restructuring of Atlantic convective clouds, Geophys. Res. Lett., 32, L14828, doi:10.1029/2005GL023187, 2005.

Levin, Z., Ganor, E., and Gladstein, V.: The effects of desert particles coated with sulfate on rain formation in the eastern Mediterranean, J. Appl. Meteor., 35, 1511-1523, 1996.

Levin, Z., Teller, A., Ganor, E., and Yin, Y.: On the interactions of mineral dust, sea salt particles and clouds - Measurements and modeling study from the MEIDEX campaign, J. Geophys. Res, 110, D20202, doi:10.1029/2005JD005810, 2005.

Lohmann, U. and Feichter, J.: Global indirect aerosol effects: a review, Atmos. Chem. Phys., 5, 715-737, 2005,

SRef-ID: 1680-7324/acp/2005-5-715.

Low, T. B. and List, R.: Collision coalescence and breakup of raindrops: Part I. Experimentally established coalescence efficiencies and fragments size distribution in breakup, J. Atmos. Sci. 39, 1591-1606, 1982a.

Low, T. B. and List, R.: Collision coalescence and breakup of raindrops: Part II. Parameterization of fragment size distributions in breakup, J. Atmos. Sci. 39, 1607-1618, 1982b.

Mather, G. K.: Coalescence enhancement in large multicell storms caused by the emissions from a kraft paper mill, J. Appl. Meteor., 30, 1134-1146, 1991.

McFarquhar, G. M., Platnick, S., Di Girolamo, L., Wang, H., Wind, G., and Zhao, G.: Trade wind cumuli statistics in clean and polluted air over the Indian Ocean from in situ and remote sensing measurements, Geophys. Res. Lett., 31, L21105, doi:10.1029/2004GL020412, 2004.

Meyers, M. P., DeMott, P. J., and Cotton, W. R.: New primary icenucleation parameterizations in an explicit cloud model, J. Appl. Meteor., 31, 708-721, 1992.

Norris, J. R.: Has Northern Indian Ocean cloud cover changed due to increasing anthropogenic aerosol?, Geophys. Res. Lett., 28, 3271-3274, 2001.

Phillips, V. T. J., Choularton, T. W., Blyth, A. M., and Latham, J.: The influence of aerosol concentrations on the glaciation and precipitation of a cumulus cloud, Quart. J. Roy. Meteor. Soc., 128, 951-971, 2002.
Pruppacher, H. R. and Klett, J. D.: Microphysics of clouds and precipitation, Kluwer Acad., 1954 p., 1997.

Ramanathan, V., Crutzen, P. J., Kiehl, J. T., and Rosenfeld, D.: Aerosols, climate and the hydrological cycle, Science, 294, 2119-2124, 2001.

Reisin, T. G., Levin, Z., and Tzivion, S.: Rain production in convective clouds as simulated in an axisymmetric model with detailed microphysics. Part II: Effects of varying drops and ice initiation, J. Atmos. Sci., 53, 1815-1837, 1996.

Reisin, T. G., Yin, Y., Levin, Z., and Tzivion, S.: Development of giant drops and high reflectivity cores in Hawaiian clouds: $\mathrm{Nu}-$ merical simulation using a kinematic model with detailed microphysics, Atmos. Res., 45, 275-297, 1998.

Rosenfeld, D.: Suppression of rain and snow by urban and industrial air pollution, Science, 287(5459), 1793-1796, 2000.

Rosenfeld, D., Rudich, Y., and Lahav, R.: Desert dust suppressing precipitation: A possible desertification feedback loop, Proc. Natl. Acad. Sci. USA, 98, 5975-5980, 2001.

Rosenfeld D., Lahav, R., Khain, A., and Pinsky, M.: The role of seaspray in cleansing air pollution over ocean via cloud processes, Science, 297, 1667-1670, 2002.

Rudich, Y., Khersonsky, O., and Rosenfeld, D.: Treating clouds with a grain of salt, Geophys. Res. Lett., 29, 2060, doi:10.1029/2002GL016055, 2002.

Twomey, S. A.: The nuclei of natural cloud formation, Part II: The supersaturation in natural clouds and the variation of cloud droplet concentrations, Geofis. Pura. Appl., 43, 243-249, 1959.

Tzivion, S., Feingold, G., and Levin, Z.: An efficient numerical solution to the stochastic collection equation, J. Atmos. Sci., 44, 3139-3149, 1987.

van den Heever, S. C., Carrio, G., Cotton, W. R., DeMott, P. J., and Prenni, A. J.: Impacts of nucleating aerosol on Florida convection. Part I: Mesoscale simulations the impact of hail size on simulated supercell storms, J. Atmos. Sci., accepted, 2005.

Warner, J.: A reduction in rainfall associated with smoke from sugar-cane fires - An inadvertent weather modification?, J. Appl. Meteor., 7, 247-251, 1968.

Warner, J. and Twomey, S.: The production of Cloud Nuclei by cane fires and the effects on cloud droplet concentration, J. Atmos. Sci., 24, 704-706, 1967.

Woodcock, A. H. and Jones, R. H.: Rainfall trends in Hawaii, J. Appl. Meteor., 9, 690-696, 1970.

Yin, Y., Levin, Z., Reisin, T. G., and Tzivion, S.: The effect of giant cloud condensation nuclei on the development of precipitation in convective clouds - A numerical study, Atmos. Res., 53, 91-116, 2000.

Yin, Y., Wurzler, S., Levin, Z., Reisin, T. G., and Tzivion, S.: Interactions of mineral dust particles and clouds: Effects on precipitation and cloud optical properties, J. Geophys. Res., 107, doi:10.1029/2001JD001544, 2002. 